\title{
$\widehat{A}$ Madridge \\ madridge Journal of Dentistry and Oral Surgery \\ Interconnecting Scientific World
}

Research Article

Open Access

\section{Two-stage Lateral Maxillary Sinus Lift using Autogenous Bone and $\beta$-Tricalcium Phosphate: Clinical and Histomorphometric Evaluation}

\author{
Radek Mounajjed $^{1,2 *}$, Jakub Strnad ${ }^{3}$, and Miguel Cevallos Lecaro ${ }^{1}$ \\ 'D.C.M. Dental Clinic, Hradec Králové, Czech Republic \\ 'Institute of Dentistry and Oral Sciences, Palacky University, Olomouc, Czech Republic \\ ${ }^{3}$ Lasak Co Ltd., Prague, Czech Republic
}

\section{Article Info}

\section{*Corresponding author: \\ Radek Mounajjed \\ D.C.M. Dental Clinic \\ Hradec Králové \\ Czech Republic \\ E-mail: mounajjed@me.com}

\section{Received: May 2, 2020}

Accepted: July 10, 2020

Published: July 20, 2020

Citation: Mounajjed R, Strnad J, Cevallos Lecaro M. Two-stage Lateral Maxillary Sinus Lift using Autogenous Bone and $\beta$-Tricalcium Phosphate: Clinical and Histomorphometric Evaluation. Madridge J Dent Oral Surg. 2020; 5(1): 96-100. doi: $10.18689 / \mathrm{mjdl}-1000122$

Copyright: ( $) 2020$ The Author(s). This work is licensed under a Creative Commons Attribution 4.0 International License, which permits unrestricted use, distribution, and reproduction in any medium, provided the original work is properly cited.

Published by Madridge Publishers

\begin{abstract}
Background: To assess the clinical and histomorphometric data of the new bone tissue from a mixture of autologous bone and $\beta$-tricalcium phosphate.

Materials and methods: A total of 72 two-stage sinus lift were performed in 54 patients during 2007 to 2010 . The autologous bone was harvested from the mandibular ramus and mixed with the $\beta$-tricalcium phosphate Poresorb ${ }^{\circledR}$ TCP sized 1-2 mm. The materials were used in a proportion ranged between 1:1 and 1:3. After the healing period a total of 119 implants were placed and 10 samples of the regenerated bone were collected for the histomorphometric analysis. CBCT or panoramic X-rays were performed presurgically, before the implant placement, six months after implant placement and then yearly to evaluate the bone formation and marginal bone loss. The implant success rate was determined using the Albrektsson et al. Criteria.

Results: The mean of the residual bone was $4.07 \mathrm{~mm} \pm 1.87 \mathrm{~mm}$. The bone gain in the sinus was $11.91 \mathrm{~mm} \pm 2.80 \mathrm{~mm}$. The implant success rate was $94.95 \%$. The histomorphometric measurements on the biopsies showed a bone area mean of $39.7 \pm$ $9.71 \%$. The residual allograft area was $16.21 \pm 8.78 \%$. The connective tissue was $44.16 \pm$ $5.85 \%$
\end{abstract}

Conclusion: Within the limit of this study, the osteoconductive $\beta$-tricalcium phosphate associated with autologous bone is a viable grafting material for sinus lift procedures. The use of composite grafts can help to reduce the morbidity and aggressivity of the bone harvesting.

Keywords: Sinus lift; Bone regeneration; Dental implants; $\beta$-tricalcium phosphate; Bone graft; Bone atrophy.

\section{Introduction}

The lack of adequate bone volume complicates the rehabilitation of the posterior edentulous maxilla with dental implants. The sinus floor elevation is an accepted treatment procedure to increase the bone in the atrophic upper jaw [1-3]. The implants can be placed simultaneously (one-stage) or delayed (two stages). The one stage procedure is recommended if the residual bone allows to stabilize the implants, and can be performed using either a lateral or transalveolar approach. In cases of severe atrophy, the sinus lift and the implant installation are preferably performed in two stages with a lateral window approach. The autogenous bone graft is the more widely used augmentation material. Because of its osteogenic, osteoconductive and osteoinductive properties is considered the gold standard for maxillary sinus floor augmentation [4-7]. 
Nevertheless, the bone harvesting usually requires an additional and sometimes an extraoral donor site, which increases the patient morbidity. The biomaterials (allogeneic bone graft, xenograft, and alloplastic materials) are presented as a suitable substitute for autogenous bone graft. Allografts and xenografts are taken from human cadavers and animals, respectively, whereas alloplasts are synthetic materials that are readily available.

Alloplastic materials such as $\beta$-tricalcium phosphate $(\beta$-TCP) are widely employed as a graft alternative to overcome the potential bone harvesting complications [8-10]. They have no risk for cross infection/disease transmission, which might be a possibility with the use of allografts and xenografts [11]. Although the alloplasts have optimal osteoconductive features, the bone formation is slower comparing with the autogenous bone. The use of $\beta$-TCP alone may take till 24 months to attain bone formation [12]. Composite grafts are advocated to combine the advantages of both materials and to reduce the disadvantages of an extensive bone harvesting [13-17]. Despite the large number of studies about sinus lift augmentation procedures, a few publications report information about the combination of autogenous bone and alloplastic materials. The aim of the present study is to assess the clinical and histomorphometric data of the new bone tissue from a mixture of autologous bone and $\beta$-TCP.

\section{Materials and Methods}

The present study involves a total of 54 adult patients with insufficient bone volume in the posterior maxilla. All the patients were treated in a private dental clinic over a period of 2007-2010. The group comprised 25 females and 29 males. The mean age was 54.7 years. All the surgery was performed by the same surgeon. A total of 73 two-stage sinus lift were accomplished. In this study were included no medically compromised patients and smokers were excluded. The residual alveolar bone height was measured on panoramic radiographs. The distance from the inferior border of the maxillary sinus to the residual ridge crest was recorded. The mean of the residual bone was $4.07 \mathrm{~mm} \pm 1.87 \mathrm{~mm}$.

\section{Surgical procedures}

Bone grafting: The surgical procedure was performed in local anesthesia. The autologous bone was harvested from the mandibular angle region with a $5 \mathrm{~mm}$ diameter trephine bur. The bone was milled and mixed with the $\beta$-TCP Poresorb ${ }^{\circledR}$ TCP (Lasak, Prague, Czech Republic) sized 1-2 mm. The materials were used in a proportion ranged between $1: 1$ and $1: 3$.

Sinus augmentation: The crestal incision was placed vestibular and the buccal releasing incisions were positioned avoiding the teeth. The full-thickness flap was raised, uncovering the lateral sinus wall. Using a steel bur, the bone window was prepared. Its dimension depended on the number of implants to be placed. After Schneiderian membrane exposition, it was carefully released from the inferior and lateral sinus walls and lifted superiorly. In case of membrane perforation, the defect was repaired with oxidized regenerated cellulose Surgicel ${ }^{\circledR}$ (Johnson \& Johnson Medical Ltd., Wokingham, UK) or collagen membrane Resodont ${ }^{\circledR}$ (RESORBA Wundversorgung $\mathrm{GmbH} \&$ Co. KG, Nürnberg, Germany).

The particulate graft was previously immersed in a sterile saline solution and suddenly packed into the sinus. The mucoperiosteal flap was sutured and primary closure was attained. The patients were medicated with $1 \mathrm{gof}$ amoxycillin + clavulanic acid Augmentin ${ }^{\circledR}$ (GlaxoSmithKline, Middlesex, UK) every 12 hours during one week after maxillary grafting. To control the inflammation and the pain after surgery was administered orally $400 \mathrm{mg}$ of Ibuprofen Apo-Ibuprofen ${ }^{\circledR}$ (Apotex Co. Toronto, Ontario, Canada) every 8 hours during five days. During two weeks after surgery the patients rinsed their mouths out with $0.12 \%$ chlorhexidine digluconate twice a day. After two weeks the sutures were removed.

Implant placement and bone sample: After the healing graft period of 6 to 9 months a total of 119 implants Tissue level Straumann ${ }^{\circledR}$ (Dental Implant System, Straumann AG, Basel, Switzerland) and 3i Biomet ${ }^{\circledR}$ (Implant Innovations, Palm Beach Gardens, Florida, USA) were placed and 10 samples of the regenerated bonewere collected for the histomorphometric analysis. The implant installation was carried out in local anesthesia. A paracrestal incision on the palate was connected with two vertical incisions that were positioned adjacent papilla to preserve it. The bone samples were harvested from 10 randomly selected patients using a $3 \mathrm{~mm}$ diameter trephine bur during the first drilling for implant placement, then the preparation was finalized according to the manufacturer's manual. The samples were submerged in $10 \%$ buffered formaldehyde and subsequently dehydrated in increasing alcohol concentrations. The implant healing period in the graft was 6 months. The fixed prosthetic treatment was accomplished according to the manufacturer's manual.

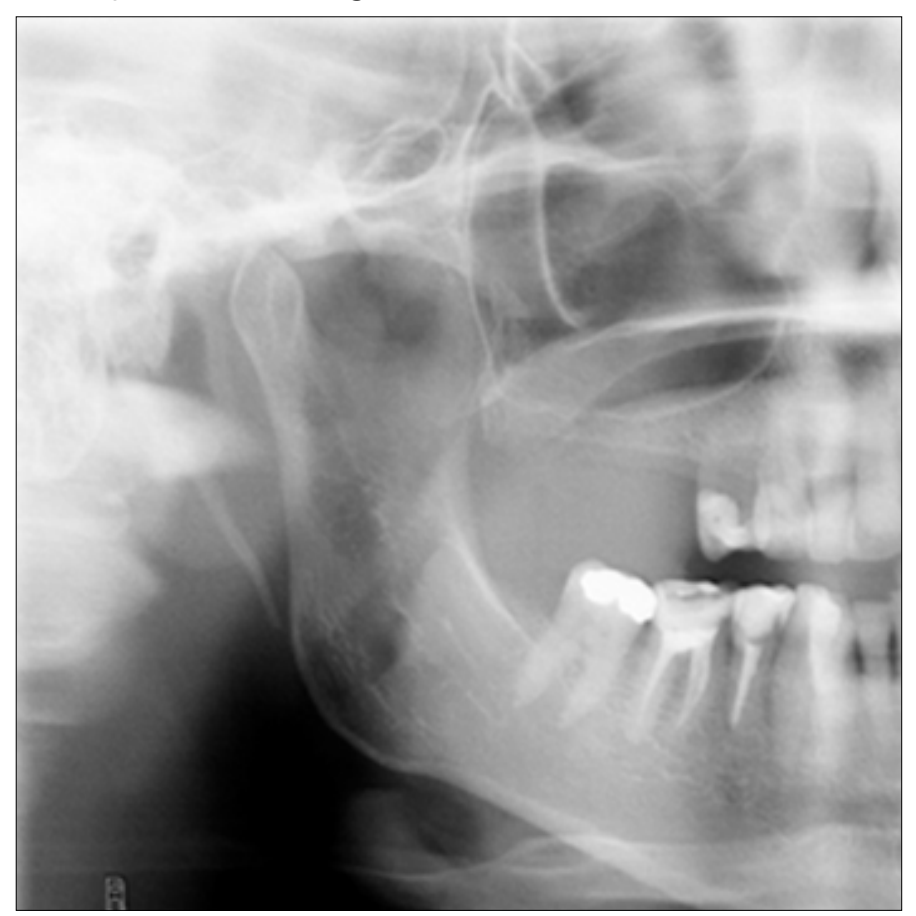

Figure 1. Preoperative panoramic radiograph before sinus grafting. 
Radiographic examination: The $\mathrm{CBCT}$ or panoramic X-rays were performed pre-surgically and before the implant placement to evaluate the bone formation (Figures 1 and $1 \mathrm{a}$ ). Intraoral X-rays were accomplished six months after implant placement and then annually to asses marginal bone loss. The success rate was determined using the Albrektsson et al. criteria [18].

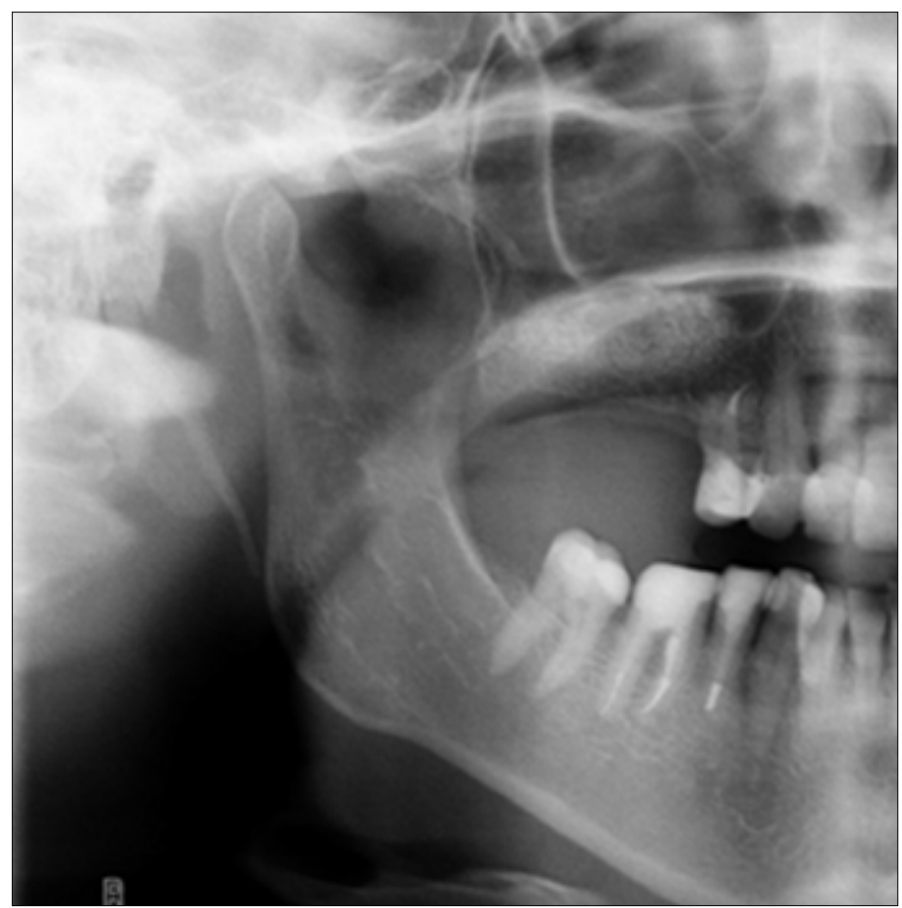

Figure 1a. Panoramic radiograph before implant installation and six months after sinus elevation.

The histomorphometric study was accomplished using Olympus BX51 Microscope and Image-Pro Plus 5.1 software. The ratio of residual material, newly formed bone and the soft tissue were evaluated. Data were estimated statistically.

\section{Results}

Fifty four patients with a total of 71 sinus lift procedures were followed in a retrospective manner. The Schneiderian membrane tearing occurs in 14 sinus operations. The postoperation period was free of complications. During the clinical follow up was assessed the oral hygiene, gingival health, and implant function. Osseous healing failure was present in 6 implants. Due these incidents the success rate was $94.95 \%$. There were not implant loss at the bone sample sites. No late failures were recorded.

Radiographic examination: At the time of the implant placement the mean of the bone gain was $11.91 \mathrm{~mm} \pm 2.80$ $\mathrm{mm}$. The new bone volume in all the cases allows the subsequent implant installation. At the 5-year follow up examination the marginal bone reduction showed minor changes.

Histology: No signs of foreign body reaction and inflammatory phenomena were observed in any of the samples. Remnant of $\beta$-TCP was present in all of the cases (Figure 2). These particles were surrounded by osseous and/or connective tissue. The newly formed bone was predominantly lamellar (Figure 3). All the samples were harvested after six months healing graft period. The obtained data are showed in the table 1.

The histomorphometric measurements on the biopsies showed a bone area mean of $39.7 \pm 9.71 \%$. The residual allograft area was $16.21 \pm 8.78 \%$. The connective tissue was $44.16 \pm 5.85 \%$.

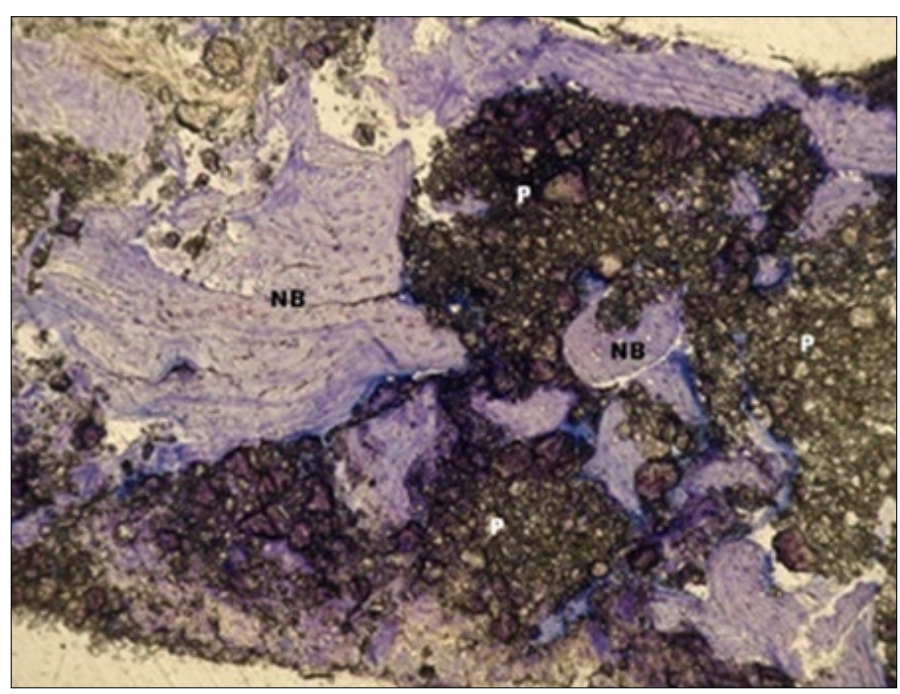

Figure 2. $\beta$-TCP granules surrounded by newly formed bone. P: Poresorb; NB: New Bone (toluidine blue; original magnification 100x)

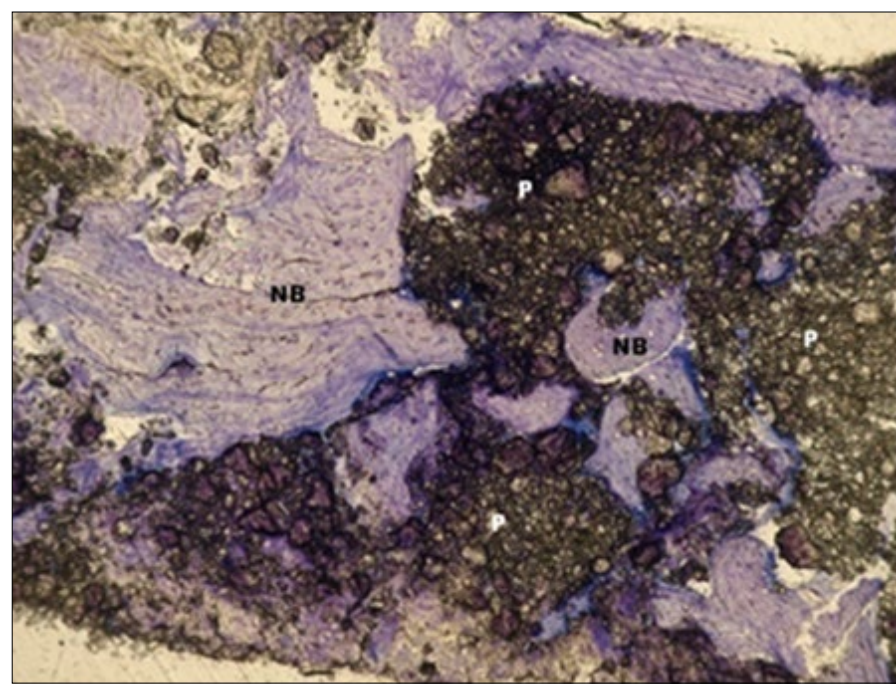

Figure 3. Autogenous bone with osteoid seams and new bone trabeculae in direct contact with $\beta$-TCP. AB: Autogenous Bone; NB: New Bone; P: Poresorb (toluidine blue; original magnification 100x).

Table 1. Percentages per case and mean of vital bone, remaining $\beta$-TCP and connective tissue six months after sinus elevation.

\begin{tabular}{|c|c|c|c|}
\hline No. Case & Vital bone $\%$ & Remaining TCP \% & Connective Tissue \% \\
\hline Case 1 & 29.75 & 22.55 & 47.69 \\
\hline Case 2 & 26.71 & 20.47 & 52.81 \\
\hline Case 3 & 25.17 & 28.54 & 46.28 \\
\hline Case 4 & 35.48 & 25.94 & 38.57 \\
\hline Case 5 & 44.25 & 15.41 & 40.33 \\
\hline Case 6 & 49.15 & 3.99 & 46.86 \\
\hline Case 7 & 50.31 & 14.11 & 35.58 \\
\hline Case 8 & 43.4 & 6.95 & 49.48 \\
\hline Case 9 & 49.8 & 4.5 & 47.15 \\
\hline Case 10 & 43.4 & 19.65 & 36.9 \\
\hline
\end{tabular}




\section{Discussion}

The sinus lift procedures offer a predictable treatment for the atrophic posterior maxilla [1-3]. The technique has undergone various modifications and diverse augmentation materials have been used. The two-stage procedure prolongs the treatment time, however the graft healing and the implant stability showed good results [19]. The fact that is not possible to solve all the cases with the one-stage modality, makes the sinus floor elevation with delayed implant placement a possible option of choice to increase maxillary bone volume. Several studies have demonstrated similar outcomes for the one-stage and the two-stage maxillary sinus floor elevation [20-22]. The perforation of the Schneiderian membrane is the most common complication of sinus augmentation [23]. In our study, fourteen perforations occur during membrane elevation. Despite of these circumstances, there were not complications after sinus grafting.

The mixture of autogenous bone and $\beta$-TCP showed in this study an overall implant success rate of $94.95 \%$ and $100 \%$ success rate after five years of loading. Long term success rate of $92.5 \%$ has been reported by Chiapasco et al. for sinus lift with autogenous bone graft [5]. In other publications, Chiapasco et al., Handschel et al., and Nkenke et al., have not found significant difference in the implant survival rates between various grafting materials [24-26].

The autogenous bone is considered as the gold standard and has been very well documented $[6,7]$. Frequently the required graft amount forces the practitioners to use extraoral donor sites, with the increase of morbidity and risk of complications. The use of composite grafts is advocated to reduce the harvested graft volume. The use of $\beta$-TCP has been well documented for the treatment of dental and maxillofacial osseous defects [8-10]. After a healing period of 6 to 9 months residual graft particles were still present. This finding is comparable to other studies using composite grafts [13-16]. The bone volume of the studied group has satisfactory results for implant placement. Szabo et al. have documented an osseous tissue mean of $36.47 \% \pm 6.9 \%$ and Wiltfang et al. founded bone formation values between 25 and $37 \%$ using only $\beta$-TCP $[27,28]$. Other authors published a bone mean of $30.7 \%$ when using composite grafts of autogenous bone and $\beta$-tricalcium phosphate [17]. The different proportions between the biomaterial and the autologous bone and the diversity of the materials used, make difficult to compare the results of this study with others. However, a lower bone quantity in the graft could not offer benefits [29].

\section{Conclusion}

Within the limit of this study, the use of $\beta$-TCP combined with autogenous bone harvested from an intraoral donor site is an adequate graft material for sinus lift procedure. The use of composite grafts can help to reduce the morbidity and aggressivity of the bone harvesting.

\section{References}

1. Lima JFM, Matos JD, Santos Í, et al. Maxillary sinus lift surgery techniques: a literature review. Int J Adv Res. 2017; 5(8): 832-844. doi: 10.21474/IJAR01/5126

2. Pjetursson BE, Tan WC, Zwahlen M, Lang NP. A systematic review of the success of sinus floor elevation and survival of implants inserted in combination with sinus floor elevation. Part I: Lateral approach. $J$ Clin Periodontol. 2008; 35(8): 216-240. doi: 10.1111/j.1600-051X.2008.01272.x

3. Raghoebar GM, Onclin P, Boven GC, Vissink A, Meijer HJA. Long-term effectiveness of maxillary sinus floor augmentation: A systematic review and meta-analysis. J Clin Periodontol. 2019; 46: 307-318. doi: 10.1111/jcpe. 13055

4. Schmitt $C M$, Doering $H$, Schmidt $T$, Lutz R, Neukam FW, Schlegel KA. Histological results after maxillary sinus augmentation with Straumann ${ }^{\circledR}$ Bone Ceramic, Bio-Oss ${ }^{\circledR}$, Puros ${ }^{\circledR}$, and autologous bone. A randomized controlled clinical trial. Clin Oral Implants Res. 2013; 24(5): 576-585. doi: 10.1111/j.1600-0501.2012.02431.x

5. Chiapasco $M$, Zaniboni $M$, Rimondini L. Dental implants placed in grafted maxillary sinuses: a retrospective analysis of clinical outcome according to initial clinical situation and a proposal of defect classification. Clin Oral Implants Res. 2008; 19(4): 416-428. doi: 10.1111/j.1600-0501.2007.01489.x

6. Kahnberg KE, Vannas-Löfqvist L. Sinus Lift Procedure Using a 2-Stage Surgical Technique: I. Clinical and Radiographic Report up to 5 Years. Int J Oral Maxillofac Implants. 2008; 23(5): 876-884.

7. Peng W, Kim K II, Cho HY, et al. Assessment of the autogenous bone graft for sinus elevation. J Korean Assoc Oral Maxillofac Surg. 2013; 39(6): 274-282. doi: 10.5125/jkaoms.2013.39.6.274

8. Bornstein MM, Chappuis V, von Arx T, Buser D. Performance of dental implants after staged sinus floor elevation procedures: 5-year results of a prospective study in partially edentulous patients. Clin Oral Implants Res. 2008; 19(10): 1034-1043. doi: 10.1111/j.1600-0501.2008.01573.x

9. Pereira RD, Gorla LF, Boos FB, Okamoto R, Junior IR, Hochuli-Vieira E. Use of autogenous bone and beta-tricalcium phosphate in maxillary sinus lifting: histomorphometric study and immunohistochemical assessment of RUNX2 and VEGF. Int J Oral Maxillofac Surg. 2017; 46(4): 503-510. doi: 10.1016/j.jjom.2017.01.002

10. Zijderveld SA, Schulten EAJM, Aartman IHA, ten Bruggenkate CM. Long-term changes in graft height after maxillary sinus floor elevation with different grafting materials: radiographic evaluation with a minimum follow-up of 4.5 years. Clin Oral Implants Res. 2009; 20(7): 691-700. doi: 10.1111/j.1600-0501.2008.01697.x

11. Lee MJ, Kim BO, Yu SJ. Clinical evaluation of a biphasic calcium phosphate grafting material in the treatment of human periodontal intrabony defects. J Periodontal Implant Sci. 2012; 42(4): 127-135. doi: 10.5051/jpis.2012.42.4.127

12. Misch $C E$, Resnik RR, Misch-Dietsh. Maxillary sinus anatomy, pathology, and graft surgery. In: Misch CE (ed). Contemporary Implant Dentistry. Mosby. 2008: 905-974.

13. Barone A, Ricci M, Grassi RF, Nannmark U, Quaranta A, Covani U. A 6-month histological analysis on maxillary sinus augmentation with and without use of collagen membranes over the osteotomy window: randomized clinical trial. Clin Oral Implants Res. 2013; 24(1): 1-6. doi: 10.1111/j.1600-0501.2011.02340.x

14. Galindo-Moreno P, Avila G, Fernández-Barbero JE, et al. Evaluation of sinus floor elevation using a composite bone graft mixture. Clin Oral Implants Res. 2007; 18: 376-382. doi: 10.1111/j.1600-0501.2007.01337.x 
15. Lee DZ, Chen ST, Darby IB. Maxillary sinus floor elevation and grafting with deproteinized bovine bone mineral: a clinical and histomorphometric study. Clin Oral Implants Res. 2012; 23: 918-924. doi: 10.1111/j.1600-0501.2011.02239.x

16. Jensen T, Schou S, Stavropoulos A, Terheyden H, Holmstrup P. Maxillary sinus floor augmentation with Bio- Oss or Bio-Oss mixed with autogenous bone as graft: a systematic review. Clin Oral Implants Res. 2012; 23(3): 263-273. doi: 10.1111/j.1600-0501.2011.02168.x

17. Aguirre-Zorzano LA, Rodríguez-Tojo MJ, Aguirre-Urizar JM. Maxillary sinus lift with intraoral autologous bone and B - tricalcium phosphate: Histological and histomorphometric clinical study. Med Oral Patol Oral Cir Bucal. 2007; 12(7): E532-E536.

18. Albrektsson $T$, Zarb $G$, Worthington $P$, Eriksson AR. The long-term efficacy of currently used dental implants: A review and proposed criteria of success. Int J Oral Maxillofac Implants. 1986; 1(1): 11-25.

19. Wallace SS, Froum SJ. Effect of maxillary sinus augmentation on the survival of endosseous dental implants. A systematic review. Ann Periodontol. 2003; 8(1): 328-343. doi: 10.1902/annals.2003.8.1.328

20. Del Fabbro M, Testori T, Francetti L, Weinstein R. Systematic review of survival rates for implants placed in the grafted maxillary sinus. Int $J$ Periodontics Restorative Dent. 2004; 24(6): 565-577.

21. Felice P, Pistilli R, Piattelli M, Soardi E, Barausse E, Esposito M. 1-stage versus 2-stage lateral sinus lift procedures: 1-year post-loading results of a multicentre randomised controlled trial. Eur J Oral Implantol. 2014; 7(1): 65-75.

22. Kasabah $S$, Simůnek $A$, Krug J, Cevallos Lecaro M. Maxillary sinus augmentation using deproteinized bovine bone (Bio-Oss) and Impladent Dental Implant System. part I. Comparison between onestage and two-stage procedure. Acta Medica (Hradec Kralove). 2002; 45(3): 115-118.
23. Barone A, Santini S, Sbordone L, Crespi R, Covani U. A clinical study of the outcomes and complications associated with maxillary sinus augmentation. Int J Oral Maxillofac Implants. 2006; 21(1): 81-85.

24. Chiapasco $M$, Zaniboni $M$, Boisco M. Augmentation procedures for the rehabilitation of deficient edentulous ridges with oral implants. Clin Oral Implants Res. 2006; 17(2): 136-159. doi: 10.1111/j.1600-0501.2006.01357.x

25. Handschel J, Simonowska M, Naujoks C, et al. A histomorphometric meta-analysis of sinus elevation with various grafting materials. Head Face Med. 2009; 5: 12. doi: 10.1186/1746-160X-5-12

26. Nkenke E, Stelzle F. Clinical outcomes of sinus floor augmentation for implant placement using autogenous bone or bone substitutes: a systematic review. Clin Oral Implants Res. 2009; 20(4): 124-133. doi: 10.1111/j.1600-0501.2009.01776.x

27. Szabó $G$, Huys $L$, Coulthard $P$, et al. A prospective multicenter randomized clinical trial of autogenous bone versus beta-tricalcium phosphate graft alone for bilateral sinus elevation: histologic and histomorphometric evaluation. Int J Oral Maxillofac Implants. 2005; 20(3): 371-381.

28. Wiltfang J, Schlegel KA, Schultze-Mosgau S, Nkenke E, Zimmermann R, Kessler P. Sinus floor augmentation with beta-tricalciumphosphate (beta-TCP): does platelet-rich plasma promote its osseous integration and degradation? Clin Oral Implants Res. 2003; 14(2): 213218. doi: $10.1034 / j .1600-0501.2003 .140212 . x$

29. Simunek A, Kopecka D, Somanathan R, Pilathadka S, Brazda $T$. Deproteinized bovine bone versus $\beta$-tricalcium phosphate in sinus augmentation surgery: A comparative histologic and histomorphometric study. Int J Oral Maxillofac Implants. 2008; 23(5): 935-942. 